\title{
Conceptualising a framework for improving quality in primary dental care
}

\author{
Matthew Byrne*1 and Martin Tickle ${ }^{2}$
}

\section{Key points}

\begin{abstract}
This paper sets out a conceptual framework by which quality improvement in primary dental care can be approached. We argue that seeking a unified definition for quality in dentistry is a distraction to the more important end of quality improvement. An approach to quality improvement that interfaces Donabedian's domains of structure, process and outcome with various dimensions of quality gives a rational approach by which quality can be assessed and improved. The importance of valid, evidence driven indicators and methods for their implementation in primary dental care is described. Further work is required in order to identify which dimensions of dentistry are most important, but the Institute of Medicine's dimensions of safety, effectiveness, patient centreedness, timeliness, equity, efficiency are a good starting point. Trying to develop an absolute list of dimensions of quality should not distract from implementing an approach-based paradigm of quality improvement. Bioinformatics offers new solutions by which quality measures may be implemented and reported in the primary care setting. The focus of future research should be in implementing data-driven quality indicators at the level of the primary care practitioner.
\end{abstract}

\section{Introduction}

The concept of quality is complex and multifactorial. ${ }^{1}$ Many definitions for quality have been described across healthcare and the service industry, but few definitions specific to primary dental care have been offered. ${ }^{2}$ Quality improvement refers to the processes by which a body will change their practice in order to provide improved services. Validated quality measures are vital for comprehensive quality improvement. ${ }^{3,4}$ Ideally, these would be informed by a unified definition of quality. However, the complexity of the concept of quality means that obtaining a common understanding of what quality means is challenging. Priorities and the criteria to assess and improve quality will vary by context and key

${ }^{1}$ NIHR Academic Clinical Fellow in Primary Dental Care, Division of Dentistry, School of Medical Sciences, Faculty of Biology, Medicine and Health, University of Manchester; ${ }^{2}$ Professor of Dental Public Health \& Primary Care, School of Dentistry, University of Manchester

${ }^{*}$ Correspondence to: Matthew Byrne

Email: matthew.byrne-6@postgrad.manchester.ac.uk

Refereed Paper.

Accepted 30 May 2019

https://doi.org/10.1038/s41415-019-0900-8 stakeholders may have contrasting perspectives of quality based on their expectations of dental services. ${ }^{5}$ The complexity of definitively defining quality should not be a barrier to the process of quality improvement. Indeed, not knowing the location of a mountain peak should not necessarily stop one from climbing it. This paper aims to explore how an approach-based system of quality improvement may be used to inform a framework by which quality can be conceptualised and improved in primary dental care.

This paper argues that:

1. A single definition of quality may not be necessary to produce a robust framework for assessing quality in primary dental care

2. Donabedian's domains of structure, process and outcome ${ }^{6}$ provide a rational basis for conceptualising quality

3. Interfacing Donabedian's domains with disaggregated dimensions of quality, such as those expressed in the Institute of Medicine's definition, ${ }^{1}$ provides a framework which identifies areas of focus for quality measurement

4. An ideal measure of quality in primary dental care would include indicators crossing each domain and dimension of quality
5. Quality improvement should be encouraged from a bottom up approach, utilising intelligent quality measures that do not interfere with the working practices of the dentist.

\section{Difficulties with a unified definition for quality}

Simply put, the goal of quality improvement is to improve outcomes for patients. Despite this simple aim, defining quality in healthcare has been continuously attempted by a number of parties over many years. ${ }^{1,6,7,8,9,10,11,12,13,14}$ The contrasting views expressed in the published definitions provide conflicting accounts as to the relative importance of the constituent dimensions of quality. These definitions are inherently coloured by their authors' circumstances and may not be universal. This is a particular problem if definitions of quality aim to be universally relevant. Donabedian explains that the concept of quality has so many different interpretations that 'quality is whatever the methods of its assessment assess. ${ }^{15}$ While this argument is displeasingly circular, it raises the question as to whether a single definition is required. We argue that, while a specific definition for quality in primary dental 
care is not required, a common framework by which quality assessment may be approached is needed.

\section{Donabedian's domains of quality. Where do we look for quality?}

Donabedian describes an approach-based method to improving quality looking through the lenses of structure, process and outcome.

Structure refers to the physical elements of care and the organisational elements within that required to deliver care. These include the building and surgeries needed to provide care alongside the availability of staff and their training. Structures facilitate the delivery of care but do not guarantee that good quality care will be provided. ${ }^{6}$ Donabedian argues that structures must therefore be considered in terms of their sufficiency to allow for the adequate delivery of processes to allow for outcomes..$^{15}$ Measures of structure alone give poor indication of the overall quality of care. ${ }^{16}$

Process refers to any action, intervention, question or measurement performed when delivering care. Processes are objective and are often framed as the occurrence of an intervention. ${ }^{17}$ It is argued that there has been an over-reliance on process measures in healthcare that do not relate to appropriate outcomes; this is both costly and unnecessary. ${ }^{18}$

Outcome refers to changes resulting from a patient's interaction with the healthcare system. These may be objective, such as radiographic healing around a root treated tooth, or subjective, such as patient-rated outcome measures (PROMs) or patient-rated experience measures (PREMs). ${ }^{19}$ Donabedian states that the relationship between process and outcome relies on determining the causality between the two. ${ }^{15}$ When causality this is established, a measure of either the process or outcome of care can be used to infer and indicate quality. ${ }^{6,15}$ Due to the variability of outcomes between patients, they need to be considered at a population level to ensure that enough cases are available to draw conclusions on the quality of care provided by a clinician or a service; in this manner, measures of outcomes may be used to determine when processes of care do not meet professional standards. ${ }^{15}$ For Donabedian, the final health status of the patient is less important than the change in health status that has been produced by the care provided.

A logical flow from structure to process to outcomes can be perceived. The concept of quality assurance in manufacture suggests that by assessing and ensuring high quality of each structure and process in production, a high quality end product will be produced. However, one must recognise that, in healthcare, good outcomes may result from poor processes, and poor outcomes may result from good processes..$^{20} \mathrm{By}$ considering the act of improving quality through these three lenses, the need for a balanced approach to quality measurement is made clear; focusing resources on improving processes without providing sufficient structures to support this will have little effect. Furthermore, investment in structures and processes is irrational if the outcomes do not have a causal relationship to the process.

In recent years Donabedian's domains of quality have been expanded by the National Quality Measurement Clearinghouse (NQMC), to include the concepts of access and patient experience. ${ }^{21}$ However, these extra domains can be sufficiently absorbed by Donabedian's domains. For example, the concept of access naturally aligns with ensuring there is a sufficient capacity (structure) and productivity (process) within a service to facilitate care for a population. Furthermore, patient experience can be absorbed within the domains of structure, process and outcome. When considering satisfaction with care, this falls into the outcome domain. Some procedures in dentistry, such as the provision of full dentures, are such that the clinical outcome is almost wholly guided by the patient experience. When considering patient experience throughout the patient journey it may be a measurable facet of each domain, for example, satisfaction with the environment where care is delivered (structure) or with communication with the dental team or amount of discomfort associated with the procedure (processes). ${ }^{22,23}$ It may have been the intention of the NQMC to highlight the importance of ensuring patient access and patient experience in quality of care; however, they do not sufficiently add to Donabedian's domains of quality to warrant their specific inclusion to a conceptual framework of quality in dentistry.

\section{Exploring dimensions of quality in dentistry}

In essence, Donabedian's domains tell us where we need to look when considering quality, but not specifically what to look for. In exploring this, more attention needs to be paid to the various definitions of quality that have been offered. Quality is most often considered to be a multidimensional problem in which definitions are disaggregated into individual dimensions.
'Many of the dimensions developed in the literature explore the contexts of medicine and the service industry. Within healthcare, the Institute of Medicine's (IoM) six dimensions of quality are commonly cited. ${ }^{1}$ In the context of dentistry, these are also used to categorise the quality measures by the National Quality forum (NQF) and the Dental Quality Alliance (DQA) in the United States. ${ }^{24}$ This definition disaggregates dimensions of safety, effectiveness, timeliness, patient-centreedness, efficiency and equity.

Dentistry lags behind medicine in terms of understanding and measuring quality, and while these dimensions originally describing aspects of medical care are applicable to dentistry, identification of the most important dimensions of quality in dentistry will need further consideration. ${ }^{25}$ Dentistry does have some fundamental differences to primary medical care. Despite a large range of treatments in dentistry that are non-surgical and the growing paradigm of preventative, minimally interventional care, primary dental care has historically been seen as a largely surgical discipline. This means assessment of the surgical skill in which procedures are completed and the control of a patient's pain and anxiety may be areas that need to be measured to improve quality. ${ }^{2}$ Moreover, dentistry has a large and increasing volume of treatments performed for cosmetic reasons alone. ${ }^{2}$ Whether these distinctions mean that further dimensions to the IoM definition of quality are required to inform a comprehensive framework for quality in dentistry is unclear. However, while supplementary dimensions may be required for a comprehensive framework of quality in dentistry, the interface between the IoM dimensions of quality and Donabedian's domains gives a comprehensive framework by which quality measures may be developed. Figure 1 represents the interface between the domains and dimensions of care. At each point of the interface, there is scope for an indicator to be produced.

Table 1 contains a worked example showing the breadth of quality indicators that may be required to give a robust assessment of quality for providing a simple procedure such as a fissure sealant. This could be seen as being unnecessarily complex for assessing such a simple procedure and in everyday clinical practice it is unlikely that such a comprehensive assessment will be required. However, the ability to break down the constituent elements of care via a standardised framework provides clinicians and service 
Fig. 1 Diagrammatic representation of the framework of quality assessment

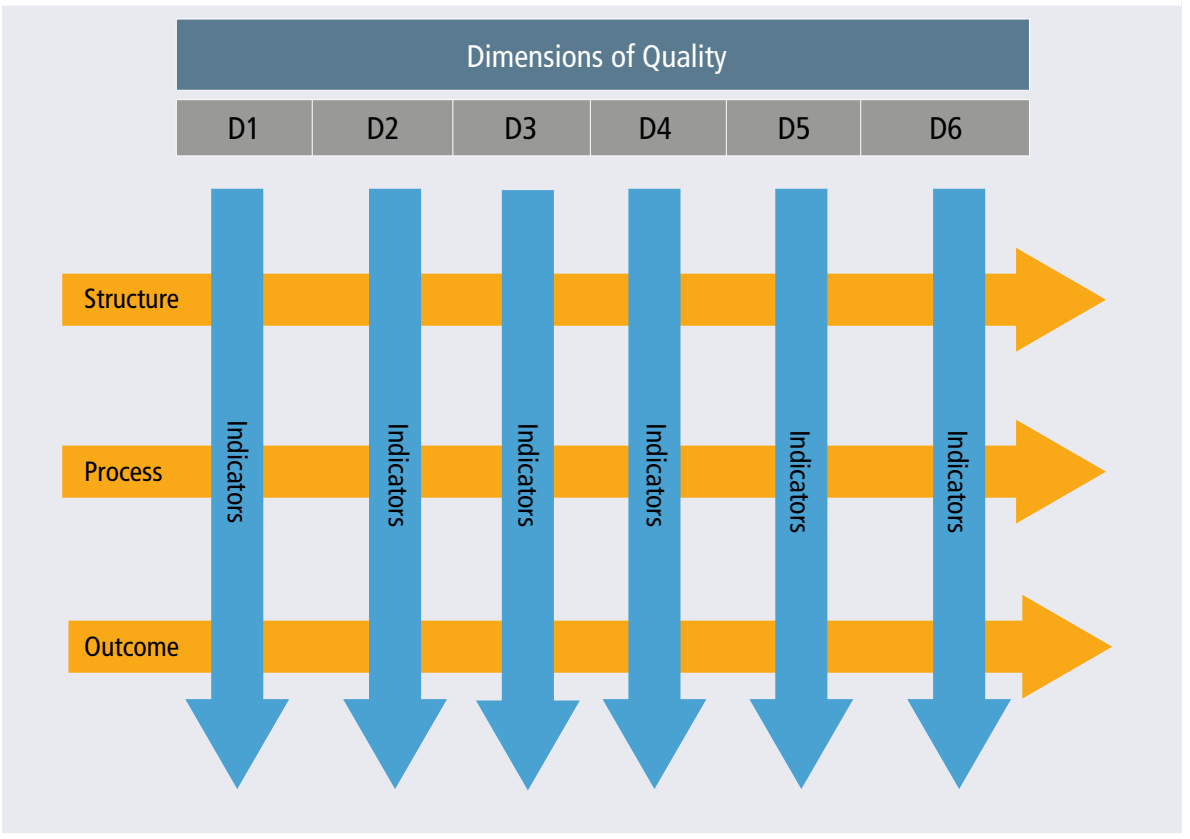

providers with the tools to forensically assess the care they provide if a significant problem with outcomes is identified. For different disciplines in dentistry or different procedures and processes a different balance between the types of indicators may be required.

\section{Steps towards implementing valid set of quality measures in dentistry based on the conceptual framework}

In this paper, the six dimensions of quality described by the IoM are used as a starting point for the dimensions of quality used to inform a framework of care. A recent RAND/UCLA appropriateness method study suggested that while these dimensions were clear and necessary for inclusion of a conceptual framework for primary dental care, further dimensions of technical quality, appropriateness, comprehensiveness and coordination and continuity of care were deemed appropriate. ${ }^{26}$ Repeating this RAND/ UCLA process in different contexts may aid to further define the important dimensions of quality. ${ }^{27}$ This, however, should not detract from the implementation of an approachbased system of quality assessment and improvement as measures may be developed alongside exiting measures in new dimensions.

The act of measuring quality influences a dentist's priorities and how they deliver care. An externally driven approach to quality improvement, imposed by insurers and health systems and rewarded with remuneration may result in a lack of ownership of quality improvement by clinicians. It also risks unintended consequences, whereby clinicians adopt a set of alternative behaviours to those intended in order to produce the required output for a quality measure. ${ }^{28}$ Accreditation systems based on clear definitions and evidencebased practice have been recognised as achieving improvements in quality in different healthcare systems. ${ }^{29}$ Ideally, the authors believe that quality improvement should be internally driven within practices and owned by clinicians for the benefit of their patients. To fulfil this goal, dentists require an appropriate set of tools to support internal assessment using formative criteria to demonstrate that a service is continually improving. Recent reviews of the dental literature identify an ever-expanding growth in the number of quality indicators. ${ }^{3,4}$ The majority of current indicators appear in the grey literature and have not been validated. The production of many of these indicators seems to be driven by requirements of service payers as part of a remuneration system or to performance manage aspects of service delivery. Their production is often pragmatically designed and implemented without testing for validity or reliability. In order to prevent the proliferation of measures from multiple sources, there have been calls to focus efforts collaboratively to construct a core quality indicator set. ${ }^{30}$

Further to the challenges of producing valid, reliable measures, we face the technical challenges of how such quality measures may be pragmatically implemented into practice. Currently, data for measures are either generated though administrative claims, patient satisfaction surveys or practice inspection and audit. ${ }^{4}$ There are limits to what data can be derived from administrative claims alone, and the vast array of different healthcare systems worldwide means that blanket application of measures would be difficult. The use of SNOMED, SNODDS and SNODENT diagnostic terminologies ${ }^{31}$ may be a helpful first step towards this but widespread adoption of these systems is problematic. Technology and electronic health records in the dental practice are becoming more prevalent, and data relevant to measuring quality may already be being recorded, but not effectively measured. If the correct data are recorded in the correct way, computerisation of health records gives scope for the routine dental

Table 1 Worked example of framework used to assess quality of a simple intervention - placement of a fissure sealant

\begin{tabular}{|c|c|c|c|c|c|c|}
\hline & Safety & Effectiveness & Timeliness & Patient centreedness & Efficiency & Equitability \\
\hline Structure & $\begin{array}{l}\text { Provided in a safe } \\
\text { environment }\end{array}$ & $\begin{array}{l}\text { Staff appropriately } \\
\text { trained }\end{array}$ & $\begin{array}{l}\text { Recall intervals that } \\
\text { allow for ideal timing }\end{array}$ & $\begin{array}{l}\text { Environment that is } \\
\text { suited to population of } \\
\text { interest }\end{array}$ & $\begin{array}{l}\text { Stock and supplies are } \\
\text { available to facilitate } \\
\text { immediate treatment }\end{array}$ & $\begin{array}{l}\text { Provided in environment } \\
\text { that fosters equal } \\
\text { opportunities for access }\end{array}$ \\
\hline Process & $\begin{array}{l}\text { Airway protected. } \\
\text { Use of rubber dam }\end{array}$ & $\begin{array}{l}\text { Use of rubber dam. } \\
\text { Correct sealant protocol } \\
\text { used and recorded }\end{array}$ & $\begin{array}{l}\text { Intervention provided } \\
\text { at appropriate age } \\
\text { related to caries risk } \\
\text { assessment }\end{array}$ & $\begin{array}{l}\text { In surgery process-related } \\
\text { experience measures. } \\
\text { Behavioural management } \\
\text { techniques employed }\end{array}$ & $\begin{array}{l}\text { Cost per unit of } \\
\text { intervention }\end{array}$ & $\begin{array}{l}\text { Distribution of } \\
\text { procedure by IMF }\end{array}$ \\
\hline Outcome & $\begin{array}{l}\text { No harm form } \\
\text { procedure - harms- } \\
\text { based trigger tool }\end{array}$ & $\begin{array}{l}\text { Retention of fissure } \\
\text { sealant. } \\
\text { Prevention of caries }\end{array}$ & $\begin{array}{l}\text { Population measures } \\
\text { - distribution of } \\
\text { intervention by age }\end{array}$ & $\begin{array}{l}\text { Patient feedback of } \\
\text { experience }\end{array}$ & $\begin{array}{l}\text { Retention of fissure } \\
\text { sealant. } \\
\text { Cost per episode }\end{array}$ & $\begin{array}{l}\text { Distribution of } \\
\text { procedure by IMF }\end{array}$ \\
\hline
\end{tabular}


inspection to provide useful data for quality assessment with minimal user input. ${ }^{32}$ The Dental Quality Alliance have developed two such dental eMeasures, entitled 'Care Continuity for Children 2-20 Years' and 'Sealants for Children 6-9 Years. ${ }^{33}$ These eMeasures have been tested for validity, reliability, feasibility and usability before acceptance by national sanctioning organisations such as the United States Health Information Knowledgebase. ${ }^{34}$ An international, coordinated collaboration could develop and apply standardised methods to test the validity and reliability of key quality indicators in each dimension of quality. This could lead to the establishment of an indicator repository providing oversight of the production and listing of validated indicators. The COMET (Core Outcome Measures in Effectiveness Trials) Initiative could provide useful learning to develop this function. ${ }^{35}$

A robust integration of bioinformatics into the measurement of quality would allow the possibility of quality assessments and assurance to happen automatically, reducing the labour required in collection and analysis of data. In a contemporary setting, measures of quality at the patient/dentist interaction level can be integrated directly and silently into a computer system, allowing dentists to view information on the quality of the care they provide immediately. ${ }^{36}$ Bioinformatics can further assist the support of quality by the introduction of clinical decision support tools into a dental electronic health record system. The aim of a clinical decision support system is to help support clinicians to make better decisions in order to improve the quality of patient care. ${ }^{37} \mathrm{~A}$ recent trial has suggested that such systems are well accepted by the dental team and high compliance with clinical decisions suggested by such a system has been achieved. ${ }^{38}$ Robust evaluation of the impact of a quality measures is required, to understand how they could be implemented into practices in a sustainable way and then to pragmatically assessing the impact of their use on the oral health of patients and the efficient working of dental practices. This process needs to be dynamic, allowing indicators that do not perform well to be retired from service to make way for new indicators.

\section{Conclusions}

Achieving a universally adopted definition of quality in dentistry may be an unachievable and an unnecessary distraction in seeking answers to the question of how to improve quality. This paper argues that the goal of quality measurement and improvement is better served by following a common approach to setting and using quality indicators than producing a formal overarching definition of quality. By using the proposed conceptual framework, priorities can be set in developing measures for use in dentistry that sufficiently cover the dimensions and domains of quality. As understanding of quality changes, there is scope for quality indicators within the framework to evolve. The challenge is now to populate such a framework with validated, reliable indicators and to evaluate if and how these improve patient care. Further clarity on the dimensions of quality that are most important to dentistry is required, however the established dimensions of the Institute of Medicine provide a rational approach that may be used and developed as our understanding of quality in dentistry grows.

\section{References}

1. Institute of Medicine Committee on Quality of Health Care in America. National Academies Press, 2001.

2. Campbell, $\mathrm{S}$, Tickle $\mathrm{M}$. What is quality primary dental care? Br Dent J 2013; 215: 135-139. DOI: 10.1038/ sj.bdj.2013.740

3. Righolt A. J, Sidorenkov, G, Faggion Jr C. M, Listl, S, Duijster D. Quality measures for dental care: A systematic review. Community Dent Oral Epidemiol 2019; 47: 12-23. DOI: 10.1111/cdoe.12429.

4. Byrne, $\mathrm{M}$ et al. A systematic review of quality measures used in primary care dentistry. Int Dent J 2018; 69: DOI: 10.1111/idj.12453

5. Riley J L 3rd, Gilbert G H, Ford G W et al. Judgement of the quality of restorative care as predictors of restoration retreatment: Findings from the National Dental PBRN. JDR Clin Trans Res 2017; 2: 151-157.

6. Donabedian A. The definition of quality and approaches to its assesment. Health Administration Press, 1980.

7. Heath, I, Rubinstein, A, Stange K C, van Driel M L. Quality in primary health care: a multidimensional approach to complexity. BMJ 2009; 338: b1242. DOI: 10.1136/bmj.b1242.

8. Poorterman J. H, Van Weert C M, Eijkman M A. Quality assurance in dentistry: the Dutch approach. Int $J$ Qual Health Care 1998; 10: 345-350.

9. Steffen G E. Quality medical care. A definition. JAMA 1998; 260: 56-61.

10. Winefield H. R, Murrell, T G, Clifford J. Process and outcomes in general practice consultations: problems in defining high quality care. Soc Sci Med 1995; 41: 969-975.

11. Blumenthal D. Part 1: Quality of carewhat is it? N Engl J Med 1996; 335: 891-894. DOI: 10.1056/ NEJM199609193351213.

12. Campbell S. M, Roland, M O, Buetow S A. Defining quality of care. Soc Sci Med 2000; 51: 1611-1625.

13. Caper P. Defining quality in medical care. Health Aff 1988; 7: 49-61. DOI: 10.1377/hlthaff.7.1.49.

14. Maxwell R J. Dimensions of quality revisited: from thought to action. Quality Health Care 1992; 1: 171-177.

15. Donabedian A. Explorations in quality assessment and monitoring: Volume 3. The methods and findings of quality assessment and monitoring. Health Administration Press, 1985

16. Birkmeyer J. D, Dimick, J B, Birkmeyer N J O. Measuring the quality of surgical care: structure, process, or outcomes? J Am Coll Surg 2004; 198: 626-632. DOI: 10.1016/j.jamcollsurg.2003.11.017.
17. Dental Quality Alliance. Paediatric oral health quality and performance measures: environmental scan. 2012.

18. Berwick D M. Era 3 for medicine and health care. JAMA 2016; 315: 1329-1330. DOI: 10.1001/jama.2016.1509.

19. Bader J D. Challenges in quality assessment of dental care. J Am Dent Assoc 2009; 140: 1456-1464. DOI: 10.14219/jada.archive.2009.0084.

20. Rupp M T. Assessing quality of care in pharmacy: remembering Donabedian. J Manag Care Spec Pharm 2018; 24: 354-356. DOI: 10.18553/ jmcp.2018.24.4.354.

21. Agency for Healthcare Research and Quality. NQMC Measure Domain Defintions. 2018. Available online at http://www.ahrq.gov/gam/summaries/domaindefinitions/index.html (accessed 16 October 2018).

22. Reissmann D. R, Hacker, T, Farhan, D, Heydecke G. The Burdens in Prosthetic Dentistry Questionnaire (BiPDQ): development and validation of a patient-based measure for process-related quality of care in prosthetic dentistry. Int J Prosthodont 2013; 26: 250-259. DOI: 10.11607/ ijp.3: 266 (2013).

23. Reissmann, D R, Semmusch J, Farhan D, Smeets R, Heiland M, Heydecke G. Development and validation of the Burdens in Oral Surgery Questionnaire (BiOSQ) J Oral Rehabil 2013; 40: 780-787. DOI: 10.1111/ joor.12092.

24. National Quality Forum. 2012.

25. Australian Commission on Safety and Quality in Health Care. NSQHS Standards Guide for Dental Practices and Services. ACSQHC, 2015.

26. Byrne M., O'Malley, L, Tickle, M, Glenny A M, Campbell, S M. A RAND/UCLA appropriateness method study to identify the dimensions of quality in primary dental care and quality measurement indicators. Br Dent $J$ 2019; accepted.

27. Fitch K, Bernstein S J, Aguilar M D et al. The RAND/ UCLA Appropriateness Method User's Manual. RAND Corporation, 2001.

28. Brocklehurst P, Price J, Glenny AM, Tickle M, Birch S, Mertz E, Grytten J. The effect of different methods of remuneration on the behaviour of primary care dentists. Cochrane Database Syst Rev 2013; CD009853. DOI: 10.1002/14651858.CD009853.pub2.

29. Pomey, M P et al. Does accreditation stimulate change? A study of the impact of the accreditation process on Canadian healthcare organisations. Implement Sci 2010 5: 31. DOI: 10.1186/1748-5908-5-31.

30. Kalenderian E, Ramoni, R, Spallek H, White J, Walji M Quality measures everywhere: The case for parsimony. J Am Dent Assoc 2018; 149: 322-326. DOI: https://doi. org/10.1016/j.adaj.2018.01.046.

31. Kalenderian E, Ramoni R B, Walji M F. Standardized dental diagnostic terminology. Health 2018; 1: 1002

32. Ramoni R B, Etolue J, Tokede 0 et al. Adoption of dental innovations: The case of a standardized dental diagnostic terminology. J Am Dent Assoc 2017; 148: 319-327. DOI: 10.1016/j.adaj.2017.01.024

33. Dental Quality Alliance. Electronic Paediatric Measures. 2016. Available online at https://www.ada.org/en/ science-research/dental-quality-alliance/dqa-measuredevelopment-reports/dqa-dental-quality-measures (accessed 8 November 2019).

34. AHRQ. United States Health Information Knowledgebase. 2018. Available online at https://ushik.ahrq.gov/mdr/ portals? system $=$ mdr\&enableAsynchronousLoading=true (accessed 16 October 2019).

35. Williamson P R, Altman D G, Bagley H et al. The C O M ET Handbook: version 1.0. Trials 2017; 18: 280. DOI: 10.1186/s13063-017-1978-4.

36. Acharya, A, Shimpi, N, Mahnke, A, Mathias, R, Ye Z. Medical care providers' perspectives on dental information needs in electronic health records. J Am Dent Assoc 2017; 148: 328-337. doi: 10.1016/j. adaj.2017.01.026.

37. Newman M G. Clinical decision support complements evidence-based decision making in dental practice. J Evid Based Dent Pract 2007; 7: 1-5. DOI: 10.1016/j. jebdp.2006.12.016.

38. Mertz E, Wides C, White J. Clinician attitudes, skills, motivations and experience following the implementation of clinical decision support tools in a large dental practice. J Evid Based Dent Pract 2017; 17: 1-12. DOI: https://doi.org/10.1016/j.jebdp.2016.10.001. 